\title{
The Mood Stabilizers Valproic Acid and Lithium Enhance Mesenchymal Stem Cell Migration via Distinct Mechanisms
}

\author{
Li-Kai Tsai ${ }^{1,2}$, Yan Leng', Zhifei Wang', Peter Leeds' and De-Maw Chuang*,' \\ 'Section on Molecular Neurobiology, National Institute of Mental Health, National Institutes of Health, Bethesda, MD, USA; ${ }^{2}$ Departments of \\ Neurology and Stroke Center, National Taiwan University Hospital and National Taiwan University College of Medicine, Taipei, Taiwan
}

\begin{abstract}
Mesenchymal stem cells (MSCs) show high potential for the therapy of several human diseases; however, the effectiveness of MSC transplantation has been hampered by the relatively poor migratory capacity of these cells toward disease target sites. This study investigated whether treatment of MSCs with two mood stabilizers - valproic acid (VPA) and lithium — would enhance cell migration and, if so, to explore the mechanisms underlying their effects. Short-term ( $3 \mathrm{~h}$ ) exposure of MSCs to a relatively high concentration (2.5 mM) of VPA markedly increased the transcript and protein levels of CXC chemokine receptor 4 (CXCR4). VPA-induced CXCR4 expression required inhibition of histone deacetylases (HDACs), including the HDACI isoform, and involved histone hyperacetylation at the promoter region of the CXCR4 gene. Notably, VPA treatment enhanced stromal cell-derived factor-I $\alpha$ (SDF-I $\alpha)$-mediated MSC migration, which was completely blocked by AMD3100, a CXCR4 antagonist. Treatment of MSCs with lithium (2.5 mM for I day) selectively elevated the transcript and protein levels of matrix metalloproteinase-9 (MMP-9) and its enzymatic activity; these effects were mimicked by inhibition or gene silencing of glycogen synthase kinase-3 $\beta$ (GSK-3 $\beta$ ). Lithium treatment also potentiated SDF-I $\alpha$ dependent MSC migration across the extracellular matrix, which was suppressed by two MMP-9 inhibitors, doxycycline and GM600I. Combining VPA and lithium treatment further increased MSC migration. Overall, VPA and lithium stimulated MSC migration through distinct targets and mediators: HDAC-CXCR4 and GSK-3 $\beta$-MMP-9, respectively.

Neuropsychopharmacology (2010) 35, 2225-2237; doi:I0.1038/npp.20I0.97; published online 7 July 2010
\end{abstract}

Keywords: CXCR4; lithium; mesenchymal stem cells; migration; MMP-9; valproic acid

\section{INTRODUCTION}

Mesenchymal stem cells (MSCs) show high potential to treat several human diseases and some MSC-related clinical trials are now underway (Bernardo et al, 2009; Parekkadan and Milwid, 2010; Clinicaltrials.gov, 2010). In addition to mechanisms for cell replacement, MSCs possess therapeutic effects for immunomodulation, trophic action, neuroprotection, and stimulation of angiogenesis (Lindvall and Kokaia, 2010; Parekkadan and Milwid, 2010). Despite these advances, MSC-based therapy still needs to be standardized and optimized (Kumar et al, 2008). One key feature of MSCbased therapy is that MSCs must find their way to disease target sites after being transplanted; however, the homing ability of MSCs toward therapeutic targets is limited (Parekkadan and Milwid, 2010; Karp and Leng Teo, 2009). Thus, enhancing the migratory capacity of MSCs to increase

*Correspondence: Dr D-M Chuang, Molecular Neurobiology Section, National Institute of Mental Health, National Institutes of Health, 10 Center Drive, MSC1363, Bethesda, MD, 20892-1363, USA, Tel: 301496 49I5, Fax: 301496 9290, E-mail: chuang@mail.nih.gov Received 22 March 2010; revised 7 June 2010; accepted 9 June 2010 the number of MSCs that are able to reach relevant disease target areas may improve the overall therapeutic efficacy of MSC transplantation.

Valproic acid (VPA) has been routinely used to treat bipolar disorder and epilepsy for decades (Koch-Weser and Browne, 1980). It is well known that VPA exerts multiple pharmacological effects, including its ability to enhance $\gamma$-aminobutyric acid (GABA) neurotransmission, while reducing glutamate and dopamine neurotransmission in the brain (Haddad et al, 2009). Recent studies have shown that VPA shows neuroprotective effects in cellular and animal models of neurodegenerative diseases, including stroke (Chuang et al, 2009). In the animal model of stroke, postinsult treatment with VPA elicits multiple beneficial effects, including infarct volume reduction, suppression of neuroinflammation, induction of neurogenesis, and improved behavioral performance (Kim et al, 2009, 2007a; Ren et al, 2004). The neuroprotective effects of VPA occur by initially inhibiting histone deacetylases (HDACs) (Göttlicher et al, 2001; Phiel et al, 2001), which have a prominent role in transcriptional regulation (Chuang et al, 2009). In some cases, VPA also inhibits the activity of glycogen synthase kinase-3 (GSK-3) by enhancing its serine 
phosphorylation to activate specific signaling pathways and transcription (Kim et al, 2005). A recent study reported that VPA enhances the expression of CXC chemokine receptor 4 (CXCR4) in hematopoietic stem cells (Gul et al, 2009). CXCR4 is an $\alpha$-chemokine receptor specific for stromal cellderived factor $1 \alpha$ (SDF-1 $\alpha$ ), a molecule endowed with potent chemotactic activity first noted in lymphocytes (Raz and Mahabaleshwar, 2009). Because MSC migration is also mediated by SDF-1 $\alpha /$ CXCR4 interaction (Kitaori et al, 2009; Thieme et al, 2009; Wang et al, 2008), it is possible that inducing CXCR4 expression may promote the migration potential of MSCs. However, whether VPA upregulates CXCR4 in MSCs and enhances the migratory capacity of MSCs remains unclear.

The Wnt signaling pathway has an essential role in development and in adult tissue homeostasis (Verheyen and Gottardi, 2010). In addition, Wnt signaling is critically involved in the regulation of MSC migration (Neth et al, 2007). Wnt pathway activation inhibits GSK-3 $\beta$, leading to upregulation of target genes (Neth et al, 2007). Lithium, which is also a frequently used major mood stabilizer (Price and Heninger, 1994), activates the Wnt downstream signaling pathway by inhibiting GSK-3 $\beta$, either directly or indirectly through serine phosphorylation of the kinase (Chuang, 2005). In addition, lithium has been shown to enhance levels of GABA, acetylcholine, and 5-hydroxytryptamine in the brain and to inhibit dopamine-mediated neurophysiological functions (Price and Heninger, 1994). Similar to VPA, lithium shows neuroprotective effects in multiple in vivo and in vitro experimental settings (Chuang and Manji, 2007). Lithium treatment has been shown to enhance the migratory capacity of MSCs (Neth et al, 2006), but the underlying mechanisms remain elusive.

In this study, we showed that VPA treatment enhanced MSC migration capacity by increasing CXCR4 expression through HDAC inhibition. Lithium treatment also promoted MSC migration accompanied by upregulation of matrix metalloproteinase-9 (MMP-9) through inhibiting GSK-3 $\beta$. Consistent with our previous observations that combined treatment with VPA and lithium produces synergistic/additive neuroprotective effects (Feng et al, 2008; Leng et al, 2008), we found that VPA and lithium co-treatment further increased the migratory capacity of MSCs.

\section{MATERIALS AND METHODS}

\section{Cells and Chemicals}

Cryopreserved rat MSCs were purchased from Cell Applications (San Diego, CA). These MSCs preserved the ability to differentiate into adipocytes and osteoblasts (Supplementary Figure 1a and $b$ ). All MSCs used in the studies were at the fifth passage of cultivation. MSCs were plated at a density of $2000 \mathrm{cells} / \mathrm{cm}^{2}$ and expanded in rat MSC culture medium (Cell Applications) at $37^{\circ} \mathrm{C}$ in a humidified atmosphere containing $95 \%$ air and $5 \% \mathrm{CO}_{2}$, according to the manufacturer's instructions. MSCs were treated with VPA ( 0.2 to $20 \mathrm{mM}$ ) and/or lithium chloride (0.5 to $20 \mathrm{mM}$ ) for different periods as mentioned in the Results section. Cells were then harvested after 4 days for subsequent experiments except immunocytochemistry, which was performed after 2 to 3 days. Chemicals used in the experiments included VPA, lithium chloride, sodium butyrate, AMD3100, doxycycline (Sigma-Aldrich, St Louis, MO), trichostatin A (TSA), GSK-3 $\beta$ inhibitor VII $(\alpha-4-$ dibromoacetophenone; Calbiochem, San Diego, CA), MS275 (Government Scientific Source, Reston, VA), SB415286 (Tocris Bioscience, Ellisville, MO), and GM6001 (Millipore, Billerica, MA).

\section{Immunocytochemistry}

MSCs cultured on chamber slides were washed with phosphate-buffered saline (PBS) and then fixed in 4\% paraformaldehyde (FD Neurotechnologies, Catonsville, MD) for $10 \mathrm{~min}$ at room temperature. After fixation, cells were blocked with 5\% normal goat serum (Sigma-Aldrich) for $2 \mathrm{~h}$ at room temperature and then incubated overnight at $4{ }^{\circ} \mathrm{C}$ with the following primary antibodies: anti-CD54 (1:100; Millipore), anti-fibronectin (1:1500; Millipore), anti-collagen type I (1:500; Millipore), anti- $\beta 1$-integrin (1:200; Millipore), anti-CD73 (1:100; Santa Cruz Biotech, Santa Cruz, CA), anti-CD90 (1:200; Millipore), anti-CD14 (1:1000; Millipore), and anti-CD45 (1:1000; Millipore). Samples were then washed and incubated for $2 \mathrm{~h}$ at room temperature with the appropriate fluorescence dye-conjugated secondary antibodies (1:200; Invitrogen, Eugene, OR). Nuclei were stained with 4', 6-diamidino-2-phenylindole (DAPI) included in the mounting medium (Vector Laboratories, Burlingame, CA). For the bromodeoxyuridine (BrdU) cell proliferation study, MSCs were incubated with $100 \mu \mathrm{M}$ BrdU (Invitrogen) for $1 \mathrm{~h}$ at room temperature. After fixation with $4 \%$ paraformaldehyde for $30 \mathrm{~min}$ at $4{ }^{\circ} \mathrm{C}$, MSCs were acidified with $1 \mathrm{~N} \mathrm{HCl}$ for $30 \mathrm{~min}$ at $45^{\circ} \mathrm{C}$, blocked with $5 \%$ normal rabbit serum (Sigma-Aldrich), and then incubated with anti-BrdU antibody (1:130; Abcam, Cambridge, MA) overnight at $4{ }^{\circ} \mathrm{C}$, followed by rabbit anti-sheep secondary antibody conjugated with fluorescein (1:200; Abcam) for $2 \mathrm{~h}$ at room temperature. Fluorescent labeling was examined using a fluorescence microscope (BX61 Olympus, Center Valley, PA) equipped with a digital camera.

\section{Quantified and Reverse Transcription-Polymerase Chain Reaction (PCR)}

Real-time quantified PCR and reverse transcription-PCR was conducted as previously described (Leng and Chuang, 2006). In brief, total RNA was extracted from cultured cells using an RNeasy Mini kit (Qiagen, Valencia, CA) according to the manufacturer's protocol. cDNA synthesis was performed from $2 \mu \mathrm{g}$ of total RNA for each sample using a cDNA Reverse Transcription Kit (Applied Biosystems, Foster City, CA) as per the supplier's instructions. Quantitative PCR reactions were run in triplicate for each sample with each primer set on a 7500 Real Time PCR System (Applied Biosystems). Taqman primers, including CXCR4, MMP-9, MMP-2, MMP-3, membrane type 1-MMP $(M T 1-M M P)$, and $\beta 1$-integrin, were used with $\beta$-actin primer (Applied Biosystems) as the internal control for each sample. For reverse transcription-PCR, the following specific primers were used: for rat CXCR4, 5'-ACTTCAA CAGGATCTTCCTGCCCA-3' (forward) and $5^{\prime}$-TGGAGCC 
TCTGCTCATGGAATTGA- $3^{\prime}$ (reverse), and for rat $\beta$-actin, $5^{\prime}$-CCACAGCTGAGAGGGAAATCG-3' (forward) and $5^{\prime}$-AG TAACAGTCCGCCTAGAAGCA-3' (reverse).

\section{Measurement of Cell Viability}

The mitochondrial dehydrogenase activity that reduces 3-(4,5-dimethylthiazol-2-yl)-2,5-diphenyl tetrazolium bromide (MTT) was used to determine cell survival in a quantitative colorimetric assay, as previously described (Leng and Chuang, 2006). MSCs were incubated with MTT $(25 \mu \mathrm{g} / \mathrm{ml})$ added directly to the growth medium for $1 \mathrm{~h}$ at $37^{\circ} \mathrm{C}$. The medium was then aspirated, and the formazan product was dissolved in dimethylsulfoxide and quantified spectrophotometrically at $540 \mathrm{~nm}$. The results are expressed as a percentage of viability of the control culture.

\section{Western Blot Analysis}

MSCs cultured in 10-cm dishes were detached by scraping and sonicated for $35 \mathrm{~s}$ in ice-cold lysis buffer. Lysates were measured for protein concentrations using a BCA Protein Assay (Thermo Scientific, Rockford, IL), as previously described (Leng and Chuang, 2006). Equal amounts of protein from each sample were loaded into a $4-12 \%$ Nupage Bis-Tris gel (Invitrogen), and then subjected to electrophoresis. After separation, proteins were transferred to a nitrocellulose membrane (Invitrogen), blocked with milk, and incubated overnight at $4{ }^{\circ} \mathrm{C}$ with a primary antibody against CXCR4 (1:500; Abcam), acetylated histone-H3 on Lys9 and Lys14 (1:2000; Upstate Biotechnology, Lake Placid, NY), MMP-9 (1:1000; Millipore), GSK-3 $\beta$ (1:2000; BD, Franklin Lakes, NJ), phospho-GSK-3 $\beta^{\text {Ser9 }} \quad(1: 1000$; Cell Signaling, Beverly, MA), phospho-GSK- $3 \alpha \beta^{\text {Tyr279/216 }}$ (1:300; Upstate Biotechnology), GSK-3 $\alpha$ (1:4000; Santa Cruz Biotech), or $\beta$-actin (1:30 000; Sigma-Aldrich), in $0.1 \%$ Tween 20/PBS and then with an HRP-labeled secondary antibody (1:2000; GE Healthcare, Chalfont, UK) at room temperature for $2 \mathrm{~h}$. The reactive bands were visualized by detecting chemiluminescence on the membrane. Semiquantitative evaluation of the bands was performed by densitometric analysis and the protein expression levels were normalized to that of the house-keeping gene $\beta$-actin.

To analyze MMP-9 levels in culture medium, MSCs were cultured in $2.5-\mathrm{cm}$ dishes with $1 \mathrm{ml}$ culture medium for 1 day. A total of $750 \mu \mathrm{l}$ of the culture medium was then incubated with $200 \mu \mathrm{l}$ Gelatin-Sepharose 4B beads (GE Healthcare) for $1 \mathrm{~h}$ at $4{ }^{\circ} \mathrm{C}$. The beads were collected after centrifugation, and bound MMP-9 was eluted by incubation with $100 \mu$ l elution buffer ( $10 \%$ dimethyl sulfoxide, $5 \mathrm{mM}$ $\mathrm{CaCl}_{2}, 0.05 \%$ Brij-35, and $0.02 \% \mathrm{NaN}_{3}$ in Tris-buffered saline, $\mathrm{pH}$ 7.4) for $30 \mathrm{~min}$ at $4{ }^{\circ} \mathrm{C}$ with gentle shaking. Aliquots of $30 \mu \mathrm{l}$ of samples were then electrophoretically separated as described above.

\section{Chromatin Immunoprecipitation Assay}

Chromatin immunoprecipitation (ChIP) assays were performed using the ChIP-IT Express Magnetic Kit (Active Motif, Carlsbad, CA) as previously described (Leng and Chuang, 2006). In brief, MSCs were treated with or without
VPA for $24 \mathrm{~h}$, cross-linked with $37 \%$ formaldehyde (MG Scientific, Pleasant Prairie, WI), and then lysed, followed by centrifugation. The nuclear pellet was resuspended in shearing buffer and sonicated at $30 \%$ power, $5 \times 20 \mathrm{~s}$ to shear DNA into 200-1500 bp fragments. An aliquot of the DNA mixture $(10 \mu \mathrm{l})$ was taken for 'input DNA' analysis, which was further used as an internal control. An equal amount of the protein/DNA complex was then incubated with magnetic beads in the presence of an antibody against acetylated histone- $\mathrm{H} 3(3 \mu \mathrm{g})$ at $4{ }^{\circ} \mathrm{C}$ overnight. Immunoprecipitated DNA was then eluted, the cross-linking was reversed, and the DNA was purified. The CXCR4 promoter region was PCR amplified for 36 cycles using forward primer $5^{\prime}$-AGCCGAGTAGCCCTCAGTGTCC- $3^{\prime}$ and reverse primer 5'-CCATTTCGTTCTCACCCTGTGC-3'.

\section{Chamber Migration Assay}

Chemotaxis was assayed using modified 10-well Boyden chambers and polycarbonate membrane filters with an $8-\mu \mathrm{m}$ pore size (Neuro Probe, Gaithersburg, MD), with or without coating. For coating, membranes were incubated with human extracellular matrix (BD) at $1.4 \mu \mathrm{g} / \mu \mathrm{l}$ for $2 \mathrm{~h}$ at $37^{\circ} \mathrm{C}$, and then dried overnight at room temperature under sterile conditions. The dried membranes were hydrated with MSC culture medium for $30 \mathrm{~min}$ at $37^{\circ} \mathrm{C}$ before experimentation. Prewarmed MSC culture medium containing rat SDF- $1 \alpha$ (Prospec, Rehovot, Israel) was added to the lower chambers. Aliquots of the cell suspension $\left(1 \times 10^{5}\right.$ cells/ $100 \mu \mathrm{l}$ ) were loaded onto the upper chambers and incubated for 18 or $24 \mathrm{~h}\left(37^{\circ} \mathrm{C}, 5 \% \mathrm{CO}_{2}\right)$. After incubation, cells on the top surface of the filters were removed. Cells that had migrated into the lower compartment and attached to the lower surface of the filter were counted after fixation with $4 \%$ paraformaldehyde for $5 \mathrm{~min}$ and staining with DAPI. Migratory capacity was expressed as a migration index, which was the ratio of cell migration number in a given condition over that of the respective control. Each measurement was derived from at least three independent experiments.

\section{Zymography for MMP Enzymatic Activity}

MSCs with or without lithium treatment were lysed with lysis buffer $\left(5 \mathrm{mM} \mathrm{CaCl} 2,0.05 \%\right.$ Brij- $35,0.02 \% \mathrm{NaN}_{3}$, and $1 \%$ Triton X-100 in Tris-buffered saline, $\mathrm{pH}$ 7.4). After sonication for $35 \mathrm{~s}, 0.6 \mathrm{mg}$ protein in $554 \mu \mathrm{l}$ was incubated with $200 \mu \mathrm{l}$ Gelatin-Sepharose $4 \mathrm{~B}$ beads for $1 \mathrm{~h}$ at $4{ }^{\circ} \mathrm{C}$ with gentle rotations. The beads were collected by centrifugation and the MMP-2 and MMP-9 were eluted by incubation with $100 \mu \mathrm{l}$ elution buffer for $30 \mathrm{~min}$ at $4{ }^{\circ} \mathrm{C}$ with gentle shaking. Equal amounts of samples $(30 \mu \mathrm{l})$ were electrophoretically separated on $10 \%$ Zymogram gel (Invitrogen). Gels were washed with renaturing buffer (Invitrogen) for $30 \mathrm{~min}$ at room temperature and incubated in developing buffer (Invitrogen) overnight at $37^{\circ} \mathrm{C}$. Gels were then briefly washed with water and stained with SimplyBlue Safestain (Invitrogen) for $90 \mathrm{~min}$ when the clear bands of gelatinolysis appeared on a dark blue background. The gels were dried and scanned for densitometry. 


\section{Lentiviral shRNA Gene Knockdown}

GSK-3 $\beta$ Mission small hairpin RNA (shRNA) plasmids and non-targeting shRNA control vector (Sigma-Aldrich) were used for GSK-3 $\beta$ knockdown. shRNAs were designed against GSK-3 $\beta$ mRNA, and the sequences were $5^{\prime}$-CCG GCATGAAAGTTAGCAGAGATAACTCGAGTTATCTCTGC TAACTTTCATGTTTTT-3' ${ }^{\prime}$ (no. 615) and 5'-CCGGCGGGA CCCAAATGTCAAACTACTCGAGTAGTTTGACATTTGGG TCCCGTTTTT-3' (no. 617). The control vector produced a corresponding scrambled shRNA, with a sequence of $5^{\prime}$ CCGGCAACAAGATGAAGAGCACCAACTCGAGTTGGTGC TCTTCATCTTGTTGTTTTT-3'. Human epithelial kidney cells (HEK 293T/17) were grown in Dulbecco's modified Eagle's medium (DMEM) containing 10\% fetal bovine serum and plated onto $2.5-\mathrm{cm}$ dishes at a density of $1 \times 10^{5}$ cells per dish. The day after plating, shRNA plasmids were transfected into cells with a reagent containing $0.5 \mu \mathrm{g}$ plasmid DNA, $5 \mu \mathrm{l}$ lentiviral packaging mix (Sigma-Aldrich), and $3 \mu \mathrm{l}$ FuGENE transfection reagent (Roche, Nutley, NJ) in $2 \mathrm{ml}$ DMEM per dish. The culture medium was collected on days 2, 3, and 4 after transfection; $2 \mathrm{ml}$ fresh medium was added after each collection. The collected culture medium containing lentiviral vectors was immediately added to the $2.5-\mathrm{cm}$ dishes containing cultured MSCs. After incubation for $30 \mathrm{~h}$, MSCs were harvested for protein analysis.

\section{Statistical Analyses}

Values are expressed as mean \pm SEM from at least three independent experiments. Statistical significance was analyzed by either one-way (one variable) or two-way (two variables) ANOVA followed by LSD post hoc comparisons. Two-tailed $P$-values of $<0.05$ were considered statistically significant. The SPSS software was used for statistical analyses.

\section{RESULTS}

\section{Stem Cell Characterization}

Immunocytochemical analyses showed that almost all MSCs showed positive immunoactivity to MSC markers, including CD54 (99.7\%), fibronectin (99.4\%) (Figure 1a), collagen type I (99.3\%), $\beta 1$-integrin (99.9\%), CD90 (97.6\%), and CD73 (95.5\%) (Supplementary Figure 1c to e) (Prockop, 1997; Brooke et al, 2008; Dominici et al, 2006). In contrast, and as expected, no MSC had immunoactivity to protein markers such as CD14 (a monocyte and macrophage marker) or CD45 (a leukocyte marker; data not shown).

\section{VPA Enhanced CXCR4 Expression}

VPA treatment for $24 \mathrm{~h}$ increased CXCR4 transcript levels in MSCs in a concentration-dependent manner, as quantified by real-time PCR (Figure $1 \mathrm{~b}$ ). Because of the dramatic enhancement of CXCR 4 transcript levels by VPA $(88 \pm 12$ fold increase with $10 \mathrm{mM}$ VPA over the control), we verified CXCR4 expression by reverse transcription-PCR using different CXCR4 primer pairs. At 35 PCR cycles, CXCR4 transcript levels were higher with $10 \mathrm{mM}$ than $2.5 \mathrm{mM}$ VPA; no signal was detected without VPA treatment (Figure 1c).
At 40 PCR cycles, CXCR4 signals had reached a plateau with $2.5 \mathrm{mM}$ VPA, and only a weak band appeared without VPA treatment. These results confirmed that VPA robustly enhances the expression of CXCR4 in MSCs.

However, it was noted that treatment with VPA for $24 \mathrm{~h}$ at high doses $(>2.5 \mathrm{mM})$ induced morphological changes characterized by formation of abnormal cytoplasmic vacuoles in MSCs (Figure 1d). In addition, VPA inhibited MSC proliferation revealed by BrdU incorporation in a dose-dependent manner, with a significant effect noted even at concentrations of $0.2 \mathrm{mM} \mathrm{VPA}$ (Figure 1e). These adverse effects were prevented by short-term $(3 \mathrm{~h})$ VPA treatment followed by culture in fresh medium (drug washout; Figure $1 \mathrm{~d}$ and $\mathrm{f}$ ). Using an MTT cell viability assay, treatment with VPA for $24 \mathrm{~h}$ at high doses (5 and $10 \mathrm{mM}$ ) caused some MSC death, and this detrimental effect was avoided by 3-h VPA treatment followed by drug washout (Supplementary Figure 2).

We then examined CXCR4 transcript levels under different VPA treatment durations (2.5-10 mM). Surprisingly, shortterm $(3 \mathrm{~h})$ VPA treatment enhanced CXCR4 transcript levels most robustly (Figure $1 \mathrm{~g}$ ). Treatment with $1 \mathrm{mM}$ VPA, which is within the plasma therapeutic levels $(0.35-1.0 \mathrm{mM})$ (McEloroy and Keck, 1995), for 1-3 days produced little or no increase in CXCR4 transcript levels. Western blotting studies confirmed that VPA elevated CXCR4 protein levels in MSCs (Figure 1h). After treatment with $10 \mathrm{mM} \mathrm{VPA}$ for $3 \mathrm{~h}$, MSCs were further incubated for various times with fresh medium (drug washout). At $3 \mathrm{~h}$ after drug washout, CXCR4 protein levels were elevated by $2.6 \pm 0.6$-fold over control. Levels of acetylated histone-H3 increased rapidly, with an almost threefold increase at $1 \mathrm{~h}$ after washout. MMP-9 levels were not significantly altered under these conditions.

\section{VPA Enhanced CXCR4 Expression Through HDAC Inhibition}

VPA treatment for $24 \mathrm{~h}$ dose dependently increased acetylated histone-H3 and tended to decrease MMP-9 levels by 14and 0.63 -fold, respectively, compared with their controls at $10 \mathrm{mM}$ (Figure $2 \mathrm{a}$ ). In contrast, levels of phospho-GSK-3 $\beta^{\text {Ser9 }}$ were unchanged. ChIP assays showed that treatment with VPA at 2.5 or $10 \mathrm{mM}$ elevated CXCR4 promoter-associated acetylated histone-H3 levels in MSCs (Figure 2b). The ability of VPA to increase CXCR4 transcript was mimicked by treatment with sodium butyrate and TSA, two structurally similar and dissimilar HDAC inhibitors that inhibit class I and II HDACs (Chuang et al, 2009). Treatment with either HDAC inhibitor for $24 \mathrm{~h}$ dose dependently increased CXCR4 transcript levels in MSCs (Figure 2c). Class I HDACs include HDAC1, HDAC2, HDAC3, and HDAC8 (Chuang et al, 2009). MS-275, an HDAC1-specific inhibitor, also enhanced CXCR4 expression in a dose-dependent manner in the concentration range of $5-50 \mu \mathrm{M}$. These results strongly suggest that VPA enhances CXCR4 expression through HDACs, including the HDAC1 isoform.

\section{VPA Promoted MSC Migration Through CXCR4 Upregulation}

Using SDF- $1 \alpha$ as a chemotactic agent in modified Boyden chamber, MSCs dose-dependently migrated from the upper 


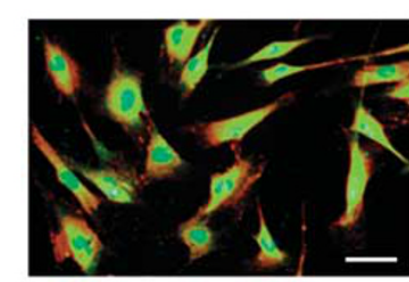

d Control

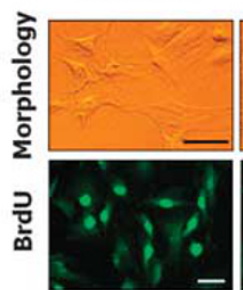

VPA

(24h) $\quad(3 \mathrm{~h}+$ washout $)$
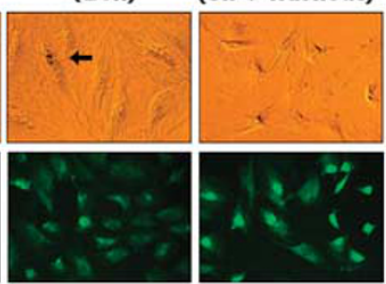

$b_{0}$

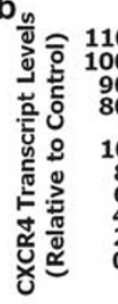

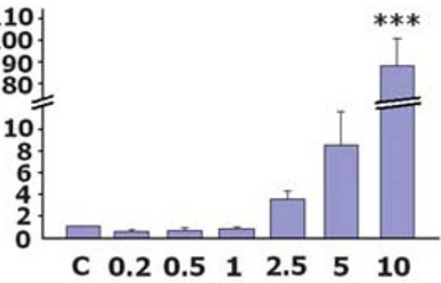

VPA (mM)

C
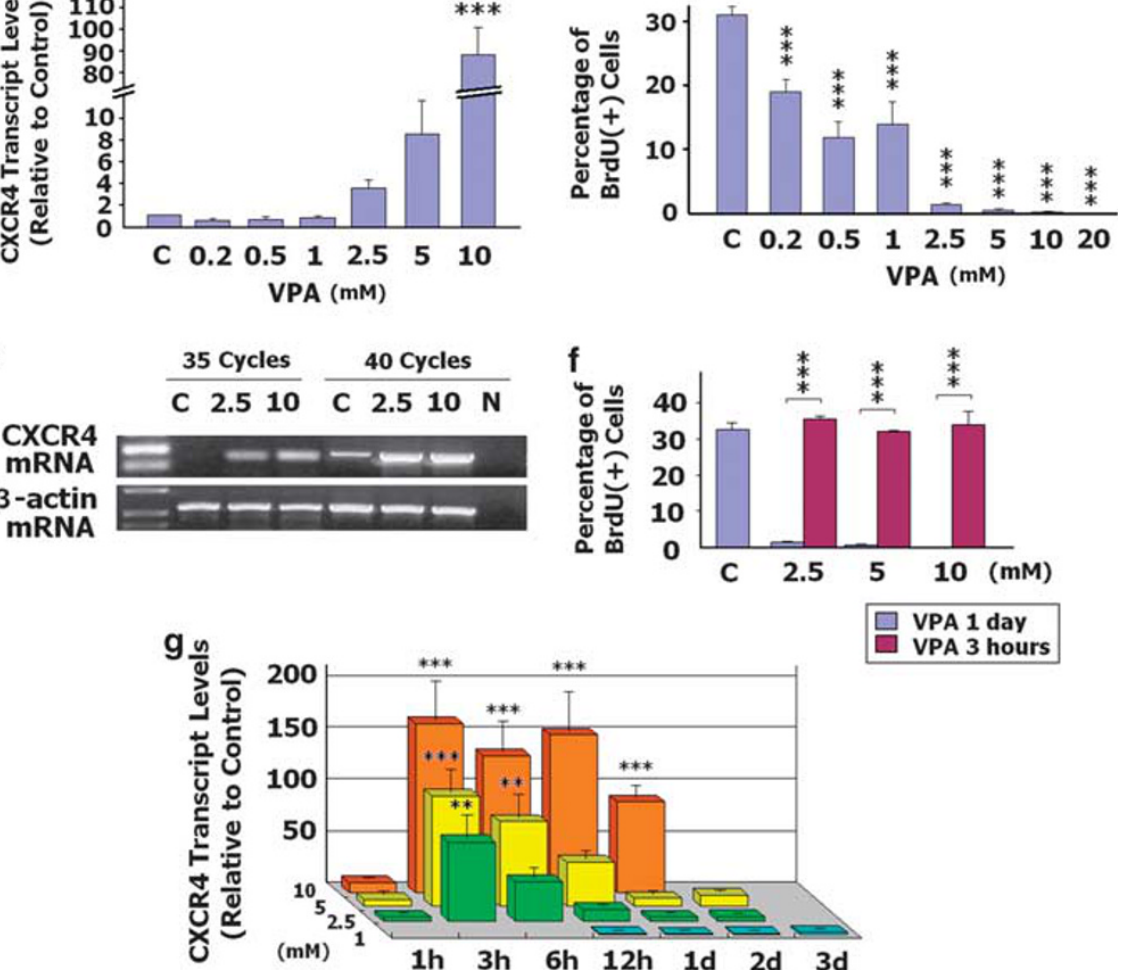

h
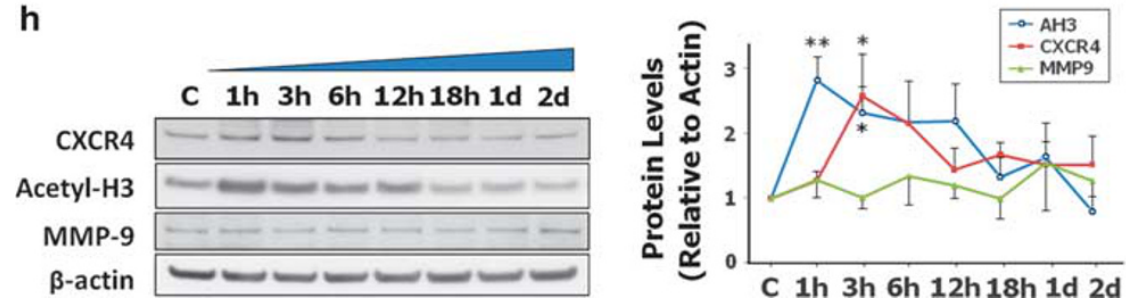

Figure I VPA treatment enhanced CXCR4 transcript and protein levels in MSCs. (a) Cultured MSCs expressed MSC markers CD54 (green) and fibronectin (red). Blue, DAPI. Bar, $50 \mu \mathrm{m}$. (b) VPA dose dependently increased CXCR4 transcript levels $24 \mathrm{~h}$ after treatment, as analyzed by quantified PCR. ' $C$ ' refers to control throughout the paper. (c) VPA increased CXCR4 transcript levels $24 \mathrm{~h}$ after treatment, as measured by reverse transcription-PCR. ' $\mathrm{N}$ ' indicates negative control without DNA polymerase. (d) After treatment with $10 \mathrm{mM}$ VPA for $24 \mathrm{~h}$, some MSCs showed cytoplasmic vacuole formation (arrow) and almost no MSCs expressed BrdU-positive immunoactivity, indicating proliferation inhibition. However, treatment with $10 \mathrm{mM}$ VPA for $3 \mathrm{~h}$ followed by culturing with fresh medium (VPA washout) for $21 \mathrm{~h}$ produced no obvious abnormal morphological changes or MSC proliferation inhibition. Bar, $50 \mu \mathrm{m}$. (e) VPA treatment for $24 \mathrm{~h}$ decreased the percentage of MSCs expressing BrdU-positive immunoactivity in a dose-dependent manner. (f) Although treatment with relatively high concentrations of VPA for $24 \mathrm{~h}$ dramatically reduced the percentage of MSCs expressing BrdU-positive immunoactivity, indicating proliferation inhibition, VPA treatment for only $3 \mathrm{~h}$ followed by VPA washout for $2 \mathrm{l} \mathrm{h}$ prevented proliferation inhibition. (g) VPA increased CXCR4 transcript levels dose dependently with the highest expression levels at $3 \mathrm{~h}$ of treatment, as analyzed by quantified PCR. (h) MSCs were treated with $10 \mathrm{mM}$ VPA for $3 \mathrm{~h}$ and then cultured with fresh medium; cells were harvested at different time points after VPA-washout. Levels of acetylated histone-H3 and CXCR4 protein peaked one and three hours after VPA washout, respectively, whereas MMP-9 levels did not change throughout the 2-day washout as determined by western blotting. Acetyl-H3 indicates acetylated histone-H3. Values are mean $\pm \mathrm{SEM}$. Data in (h) were analyzed by two-way ANOVA. * $p<0.05$; ** $p<0.0$ I; **** $<0.00$ I when compared with respective control, except in (f). 
a

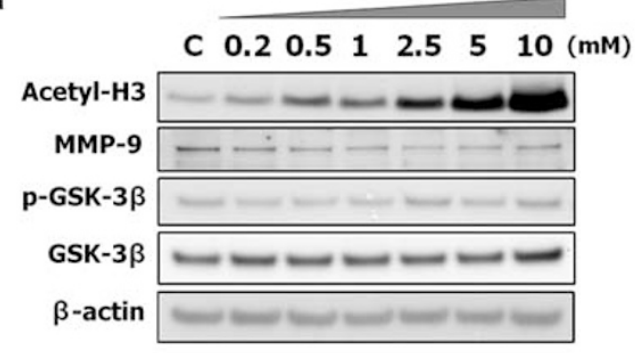

b Acetyl-H3 in CXCR4 Promoter
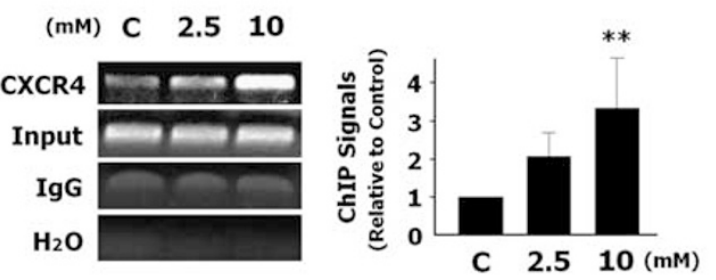
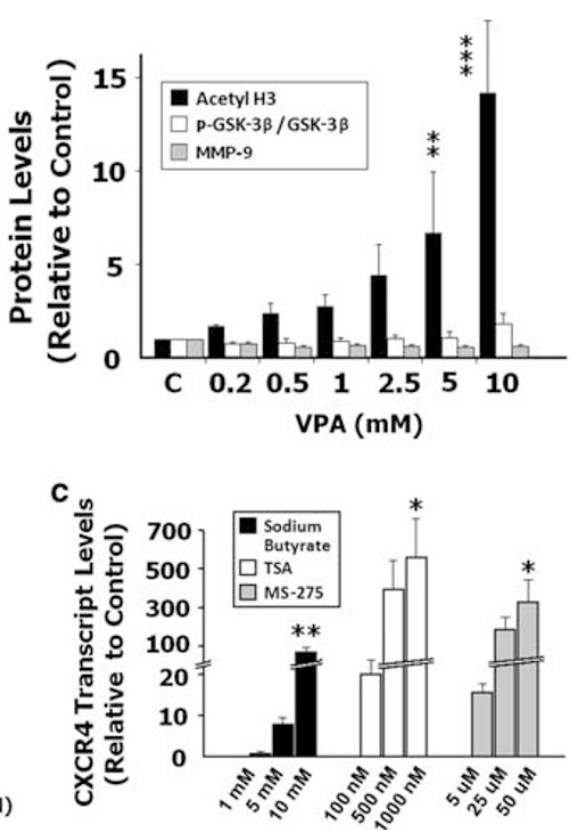

Figure 2 VPA treatment upregulated CXCR4 through HDAC inhibition in MSCs. (a) Western blotting determined that VPA treatment for $24 \mathrm{~h}$ increased acetylated histone-H3 and tended to decrease MMP-9 protein levels in a dose-dependent manner; there was no change in phospho-GSK-3 $\beta^{\text {Ser } 9}$ levels. (b) ChIP assays using acetylated histone- $\mathrm{H} 3$ antibody and a primer pair for the CXCR4 promoter region showed that VPA treatment for $24 \mathrm{~h}$ elevated CXCR4 promoter-associated acetylated histone-H3 levels. (c) Three HDAC inhibitors - sodium butyrate, TSA, and MS-275-all enhanced CXCR4 expression in a dose-dependent manner, as analyzed by quantified PCR after treatment for $24 \mathrm{~h}$. Acetyl-H3 indicates acetylated histone-H3. Values are mean \pm SEM when compared with control. Data in (a) were analyzed by two-way ANOVA. $* p<0.05 ; * * 0<0.0$ I; *** $p<0.00$ I when compared with respective control.

chamber across the membrane (without coating) to the lower chamber during the test period of $18 \mathrm{~h}$ (Figure $3 \mathrm{a}$ ). Pretreatment with $2.5 \mathrm{mM}$ VPA for $3 \mathrm{~h}$ significantly increased MSC migratory capacity (two- to three-fold increase) in the presence of either 20 or $100 \mathrm{ng} / \mathrm{ml} \mathrm{SDF-1} \alpha$ (Figure 3b). VPA did not affect the basal migratory capacity of MSCs measured in the absence of exogenous SDF- $1 \alpha$. Co-treatment of MSCs with AMD3100 $(5 \mu \mathrm{M})$, a CXCR4 antagonist, nullified the effects of VPA on cell mobility (Figure 3c). These results suggest that VPA promotes MSC migration by upregulating CXCR4.

\section{Lithium Enhanced MMP-9 Expression}

We next studied the effects of treatment with lithium, another mood stabilizer, on the migration of MSCs. We first screened the effects of lithium on levels of several migration-related transcripts in MSCs. Lithium chloride treatment dose dependently increased MMP-9 transcript levels in the concentration ranges examined (Figure 4a). Lithium also elevated CXCR4 and MMP-2 expression, but only at very high concentrations $(>5 \mathrm{mM})$. Transcript levels of MMP-3, MT1-MMP, and integrin $\beta 1$ were unchanged by lithium treatment. Western blotting revealed that lithium increased MMP-9 protein levels at a concentration of $2.5 \mathrm{mM}$, but CXCR4 protein levels did not increase even after treatment with high lithium concentrations (Figure $4 \mathrm{~b}$ ). Zymography showed that treatment with $2.5 \mathrm{mM}$ of lithium also increased MMP-9 enzymatic activity, but not that of MMP-2 (Figure 4c). The increase in MMP-9 protein levels was detected not only in MSCs, but also in the culture medium (Figure 4d), indicating that the release of MMP-9 from MSCs was also increased by lithium treatment.

To search for optimal treatment conditions for lithium, we treated MSCs with 1 or $2.5 \mathrm{mM}$ lithium chloride for different periods, and found that treatment with $2.5 \mathrm{mM}$ lithium for 1 day elicited the highest increase in MMP-9 transcript levels in MSCs (Figure 4e). We further treated the MSCs with $2.5 \mathrm{mM}$ lithium for 1 day followed by drug washout, and noted that the increase in MMP-9 protein levels persisted for at least 1 day after drug removal (Figure 4f).

\section{Lithium Enhanced MMP-9 Expression Through GSK-3 $\beta$ Inhibition}

Lithium treatment of MSCs for 1 day increased the ratio of phospho-GSK- $3 \beta^{\text {Ser9 }}$ over total GSK-3 $\beta$ levels in a dosedependent manner, whereas total GSK-3 $\beta$ levels were unchanged (Figure 5a). The lithium-induced increase of phospho-GSK-3 $\beta^{\text {Ser9 }}$ lasted for $12 \mathrm{~h}$ after drug washout (Figure 4f). Lithium treatment had no effect on levels of phospho-GSK3 $\beta^{\text {Tyr }}$ or acetylated histone-H3 (Figure 5a). These results suggest that lithium inhibits GSK-3 $\beta$ by enhancing Ser9 phosphorylation of GSK- $3 \beta$ in MSCs.

To investigate the relationship between GSK- $3 \beta$ inhibition and MMP-9 expression, we first treated MSCs with two pharmacological GSK-3 $\beta$ inhibitors. Inhibitor VII (an ATPnoncompetitive inhibitor) and SB415286 (an ATP-competitive inhibitor) increased MMP-9 protein levels in MSCs in a time- and dose-dependent manner, respectively (Figure $5 \mathrm{~b}$ ). To more specifically inhibit GSK-3 $\beta$, we then used lentiviral GSK-3 $\beta$ shRNA (615 and 617). After 
a

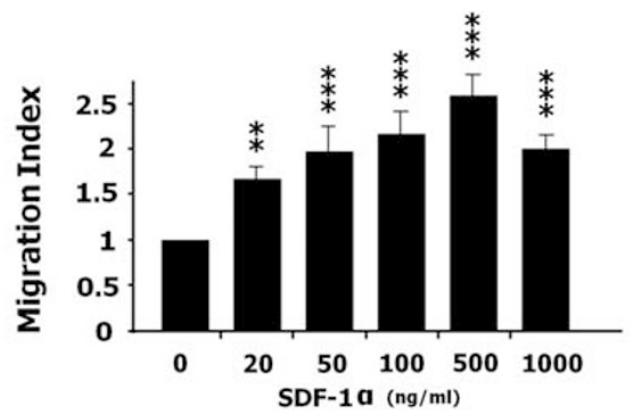

b

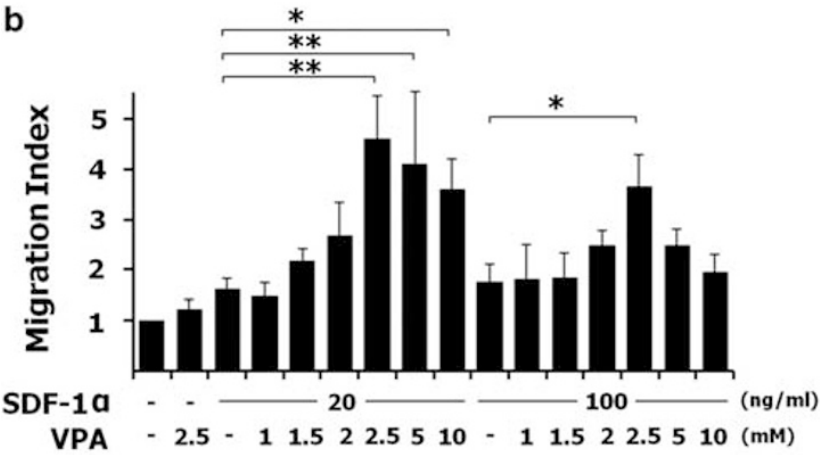

C

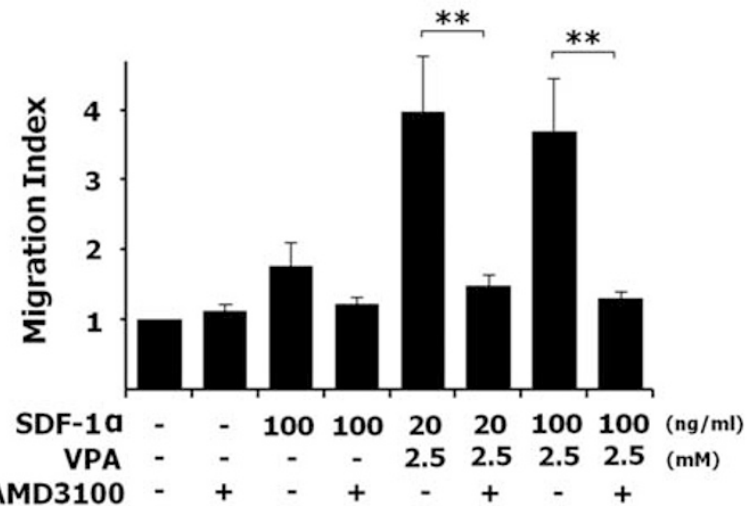

Figure 3 VPA treatment increased migratory capacity of MSCs by upregulating CXCR4. (a) Using SDF- $\alpha \alpha$ as a chemotactic agent (20$1000 \mathrm{ng} / \mathrm{ml}$ ) in a modified Boyden chamber, the migration of MSCs from the upper chamber across the membrane (without coating) to the lower chamber was measured over $18 \mathrm{~h}$. The migration index (representing migratory capacity) was the ratio of cell migration number in a given condition over that of the control. (b) Pretreatment with VPA for $3 \mathrm{~h}$ followed by drug washout increased MSC migratory capacity. (c) Copretreatment with VPA and AMD3I00 (5 $\mu \mathrm{M})$ for $3 \mathrm{~h}$ followed by drug washout nullified the effects of VPA on cell migration. Values are mean \pm SEM. $* p<0.05$; ${ }^{*} p<0.0$ I; **** $p<0.00$ I when compared with control in (a) or between indicated groups.

transfection of MSCs with the lentiviral GSK-3 $\beta$ shRNA 615, GSK-3 $\beta$ levels decreased to $57 \%$ of the shRNA-null control with a concomitant increase of MMP-9 protein levels to $188 \%$ (Figure $5 \mathrm{c}$ ). The knockdown of GSK-3 $\beta$ with lentiviral GSK-3 $\beta$ shRNA 617 was less effective in decreasing GSK-3 $\beta$ protein levels and upregulating MMP-9. Neither lentiviral shRNA affected the protein levels of CXCR4, GSK-3 $\alpha$, nor the house-keeping gene $\beta$-actin. These results strongly suggest that lithium-induced MMP-9 expression is mediated, at least in part, by GSK-3 $\beta$ inhibition.

\section{Lithium Promoted MSC Migration by Upregulating MMP-9}

To link lithium-induced MMP-9 to MSC migration, we coated the filter membranes of modified Boyden chambers with extracellular matrix, a substrate of MMP-9. Using SDF$1 \alpha$ as a chemotactic agent in the lower chamber, pretreatment with lithium for 1 day increased MSC migration in a dose-dependent manner during the test period of $24 \mathrm{~h}$ (Figure 6a). Thus, lithium at 1 and $2.5 \mathrm{mM}$ enhanced MSC migration by $38-55$ and $66-75 \%$, respectively, in the presence of 20 or $100 \mathrm{ng} / \mathrm{ml}$ of SDF- $1 \alpha$. Co-treatment of MSCs with the MMP-9 inhibitors doxycycline $(15 \mu \mathrm{g} / \mathrm{ml})$ or GM6001 $(25 \mu \mathrm{M})$ largely reduced lithium's effects on migration (Figure $6 \mathrm{~b}$ and $\mathrm{c}$ ). Together, these results suggest that lithium promotes MSC migration by upregulating MMP-9. Both MMP-9 inhibitors also robustly suppressed the migratory capacity of MSCs induced by SDF- $1 \alpha$ in the absence of lithium, suggesting that pre-existing MMP-9 in MSCs has an important role in MSC migration through the extracellular matrix.

\section{Combined VPA and Lithium Treatment Exerts Additive MSC Migratory Effects}

As shown above, VPA and lithium promoted MSC migration, likely through upregulation of CXCR4 and MMP-9, respectively. Because the two drugs enhanced migration through distinct mechanisms, we co-treated MSCs with VPA and lithium to assess possible additive effects. MSCs were treated with $2.5 \mathrm{mM}$ VPA for $3 \mathrm{~h}$ ( -6 to $-3 \mathrm{~h}$ ) and/or lithium for $24 \mathrm{~h}$ ( -24 to $0 \mathrm{~h}$ ), followed by drug washout (Figure 7a). Protein levels of CXCR4, MMP-9, acetylated histone-H3, and phospho-GSK- $3 \beta^{\text {Ser9 }}$ were all increased during $18 \mathrm{~h}$ of washout, but with different time courses (Figure 7b). Notably, CXCR4 protein levels increased with a peak at $6 \mathrm{~h}$ after washout, whereas MMP9 levels showed a trend of gradual increase over time.

MSC migratory capacity was then analyzed over a period of $24 \mathrm{~h}$ after drug washout using extracellular matrix-coated filter membranes and the chemotactic agent, SDF- $1 \alpha$. Pretreatment with VPA or lithium increased the MSC migratory capacity by $1.4-$ to 1.8 -fold or 1.6 - to 1.7 -fold, respectively, in the presence of 20 or $100 \mathrm{ng} / \mathrm{ml}$ of SDF- $1 \alpha$ (Figure 7c). Combined treatment with VPA and lithium further enhanced MSC migration by 2.9- to 3.3-fold. These additive enhancing effects were markedly diminished by the presence of AMD3100 or GM6001, and completely blocked by their co-presence (Figure $7 \mathrm{~d}$ ). These results suggest that enhancing CXCR4 and MMP-9 affects MSC migration in different ways.

\section{DISCUSSION}

This study presents evidence that treatment with VPA or lithium enhanced the migration of MSCs and elucidates the underlying mechanisms involved in upregulation of CXCR4 or MMP-9, respectively. We also showed that combined treatment with VPA and lithium additively enhanced MSC migration, further supporting the notion that different mechanisms are involved in the actions of these two agents on this phenomenon. In addition, we carefully investigated 
a

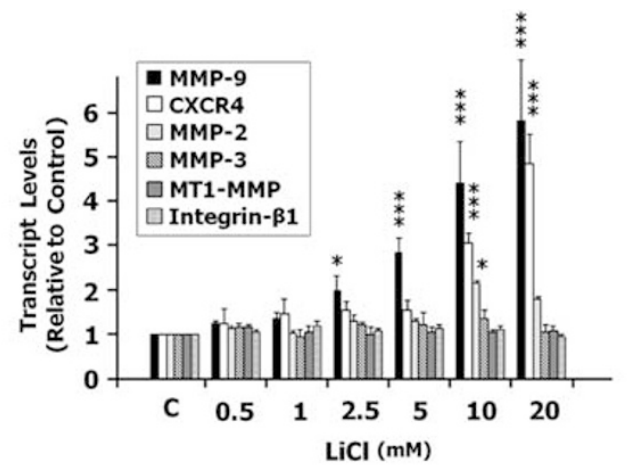

b

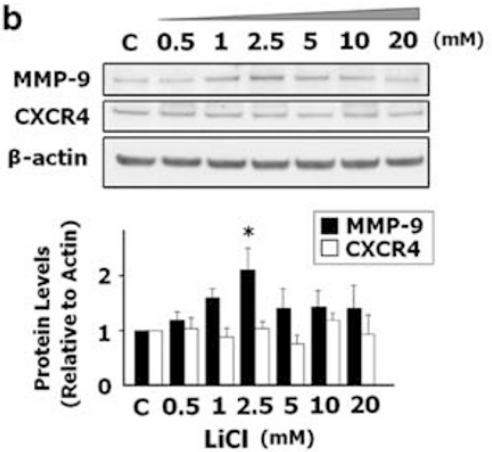

C

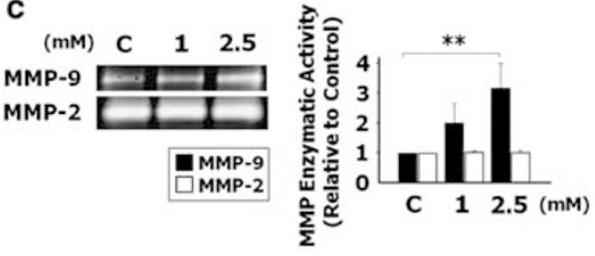

d

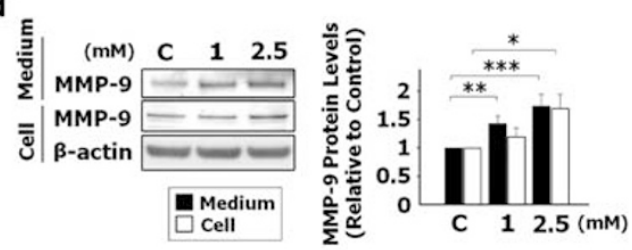

e

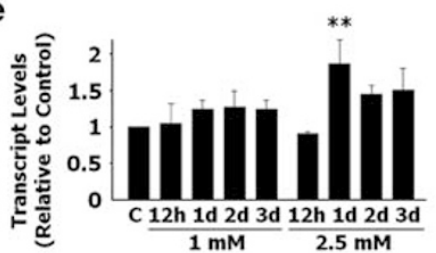

$\mathbf{f}$

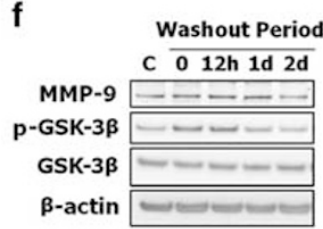

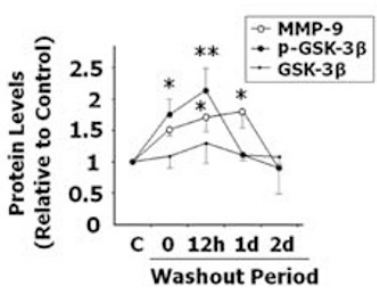

Figure 4 Lithium treatment enhanced MMP-9 transcript and protein levels in MSCs. (a) Treatment with lithium for 24h increased MMP-9 transcript levels in a dose-dependent manner, as analyzed by quantified PCR. Lithium elevated CXCR4 and MMP-2 expression only at high concentrations. (b) Lithium treatment for $24 \mathrm{~h}$ increased MMP-9 protein levels at I and $2.5 \mathrm{mM}$, but did not change CXCR4 protein levels, as determined by western blotting. (c) Lithium elevated MMP-9, but not MMP-2 enzymatic activity after treatment for $24 \mathrm{~h}$, as analyzed by MMP zymography. (d) VPA treatment for $24 \mathrm{~h}$ increased MMP-9 protein levels in both MSCs and culture medium. (e) Treatment with $2.5 \mathrm{mM}$, but not I mM, lithium increased MMP-9 transcript levels, as analyzed by quantified PCR. (f) After treatment with $2.5 \mathrm{mM}$ lithium for $24 \mathrm{~h}$ followed by culturing in fresh medium, MSCs were harvested for western blotting at different time points after lithium washout. The protein levels of phospho-GSK-3 $\beta^{\text {Ser9 }}$ and MMP-9 increased by $24-\mathrm{h}$ lithium treatment continued to rise after drug washout, with peaks at 12 and $24 \mathrm{~h}$, respectively. Data in (a-d) and ( $\mathrm{f}$ ) were analyzed by two-way ANOVA. * $<<0.05$; ** $p<0.0 \mathrm{I}$; ***** $p<0.00$ I when compared with respective control.

the optimal conditions required for VPA and lithium to upregulate CXCR4 and MMP-9 and, ultimately, to affect MSC migration. Results indicated that treatment of MSCs with $2.5 \mathrm{mM}$ VPA for $3 \mathrm{~h}$ or $2.5 \mathrm{mM}$ lithium for $24 \mathrm{~h}$ produced the most optimal effects. Recent clinical and/or preclinical studies have shown that MSC-based therapy is beneficial for the treatment of several human diseases, including cerebral ischemia (Bang et al, 2005; Dharmasaroja, 2009), myocardial infarction (Hare et al, 2009), amyotrophic lateral sclerosis (Vercelli et al, 2008), spinal cord injury (Deng et al, 2006), multiple sclerosis (Bai et al, 2009), and musculoskeletal disorders (Centeno et al, 2008). The results of this study suggest that VPA and/or lithium can be used as priming drugs to enhance the migratory capacity or homing effects of MSCs toward disease target sites after transplantation, which might expand the clinical use of these two mood stabilizers.

The role of SDF- $1 \alpha$ and CXCR4 interaction in MSC-based therapy is well recognized (Cheng et al, 2008; Segers et al, 2007; Wang et al, 2008). Until now, there has been no simple and effective way to upregulate CXCR4 in MSCs. Therefore, our finding that high concentrations of VPA are capable of robustly increasing CXCR4 transcript levels in MSCs is particularly significant. It should be noted that despite extremely high levels (up to 100-fold) of CXCR4 transcriptional upregulation by VPA, CXCR4 protein levels were increased transiently by only two- to three-fold. The disparity between CXCR4 mRNA and protein levels suggests that the synthesis and/or degradation of CXCR4 protein is tightly regulated, underscoring the complexity in the modulation of CXCR4 expression by VPA.

Although VPA inhibited MSC proliferation and caused cytotoxicity at high concentrations, a 'pulse' VPA treatment prevented these adverse effects without affecting HDAC inhibitory ability. VPA has been shown to inhibit class I (HDACs 1, 2, 3, and 8) and class IIa (HDACs 4, 5, 7, and 9) by directly binding to the active sites of these HDACs (Göttlicher et al, 2001; Phiel et al, 2001). Several lines of evidence support the notion that VPA-induced transcriptional activation of CXCR4 in MSCs is related to HDAC inhibition. First, the ability of VPA to induce CXCR4 and to promote MSC migration is dose- and time-dependently correlated with VPA-induced histone $\mathrm{H} 3$ hyperacetylation - an index of HDAC inhibition. Second, the upregulation of CXCR4 transcript is associated with histone hyperacetylation in the promoter region of the CXCR4 gene, indicating 
a

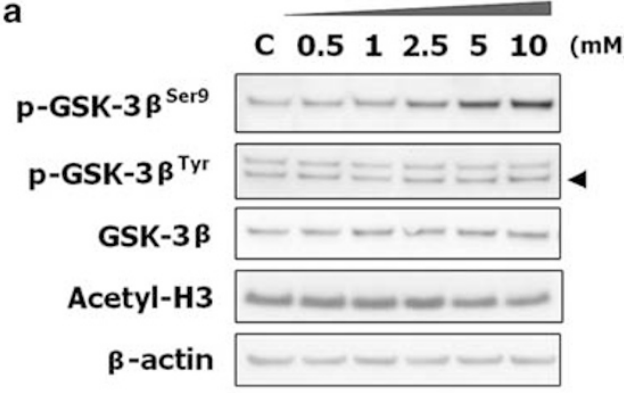

b

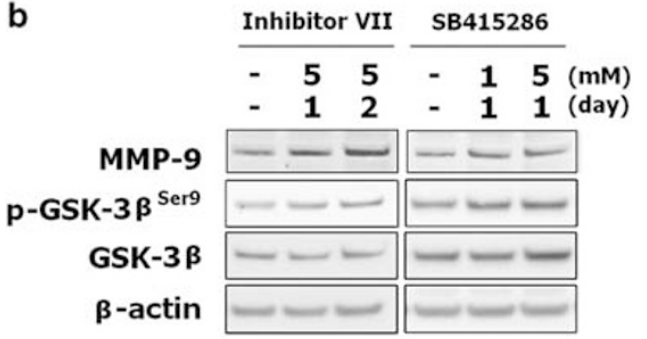

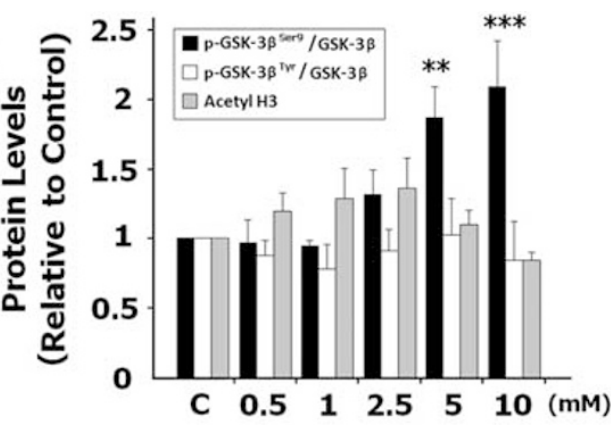

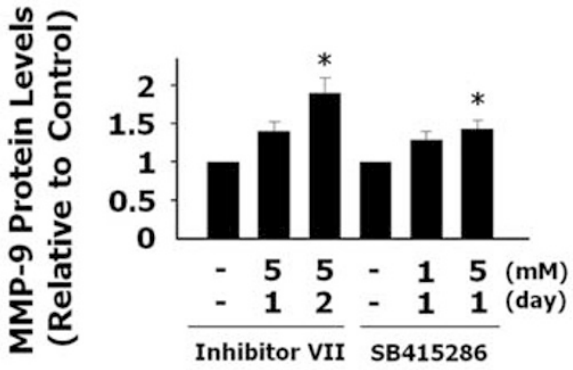

C
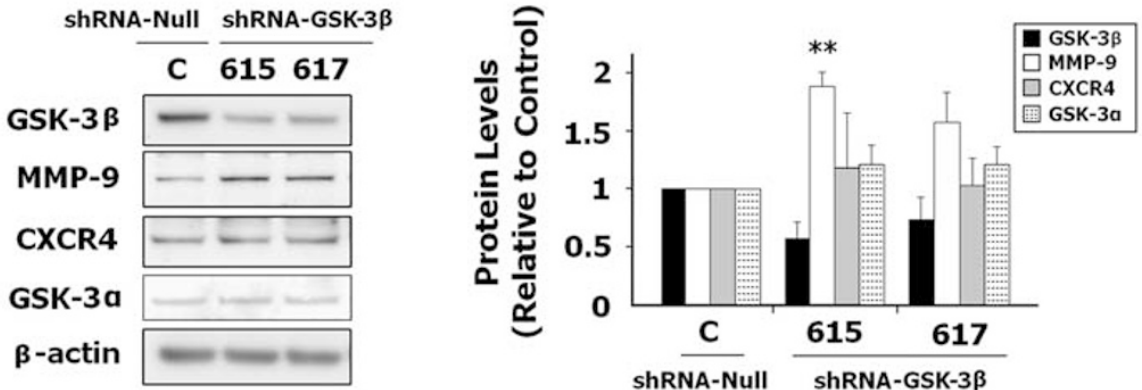

Figure 5 Lithium treatment enhanced MMP-9 expression in MSCs through GSK-3 $\beta$ inhibition. (a) Treatment with lithium for $24 \mathrm{~h}$ increased phosphoGSK-3 $\beta^{\text {Ser9 }}$ levels in a dose-dependent manner, whereas there was no change in phospho-GSK-3 $\beta^{\text {Tyr }}$ and acetylated histone-H3 levels, as determined by western blotting. (b) GSK-3 $\beta$ inhibitor VII and SB4I5286 increased MMP-9 protein levels in MSCs in a time- and dose-dependent manner, respectively. (c) After knockdown of GSK-3 $\beta$ by transfection with the lentiviral GSK-3 $\beta$ shRNA in MSCs, MMP-9 protein levels increased compared with those transfected with lentiviral null. Acetyl-H3 indicates acetylated histone-H3. Values are mean \pm SEM. Values are mean \pm SEM. Data in (a, c) were analyzed by two-way ANOVA. * $p<0.05$; ** $p<0.01$; **** $p<0.001$ when compared with control.

chromatin remodeling. Third, other HDAC inhibitors, including sodium butyrate, TSA, and MS-275, mimic the ability of VPA to increase CXCR4 mRNA levels. Sodium butyrate and TSA inhibit class I and II HDACs, whereas MS275 preferentially inhibits the HDAC1 isoform at the doses used in this study (Chuang et al, 2009). Together, our results suggest that $\mathrm{HDAC1}$ is involved in the induction of CXCR4 by VPA; however, the role of other HDAC isoforms of class I and IIa cannot be excluded.

Transcriptional regulation of CXCR4 in cancer stem cells seems to be mediated by signaling of TGF- $\beta$, nodal, and activin, and to involve several transcription factors including POU5F1, FOXA2, SOX17, and p53-GFI1 (Katoh, 2010). Interestingly, sodium butyrate potentiated the expression of SOX17 and FOXA2 in human embryonic stem cells (Jiang et al, 2007). It is also notable that CXCR4-mediated motility/ migration of human osteosarcoma cells depends on the MEK1/2, ERK, and NF- $\kappa \mathrm{B}$ signaling pathways (Huang et al, 2009). In this context, VPA has been shown to be a robust activator of MEK/ERK signaling (Einat et al, 2003), suggesting that this effect could also contribute to VPAinduced, CXCR4-mediated MSC migration.

The migratory capacity of MSCs is enhanced by activation of Wnt signaling pathways, which includes inhibition of GSK-3 $\beta$ (Neth et al, 2007). Lithium, a well-known GSK-3 $\beta$ inhibitor, enhanced MSC migration with a concomitant increase in GSK-3 $\beta^{\text {Ser9 }}$ phosphorylation. By screening the transcripts of several migration-related proteins, we found that MMP-9 was selectively upregulated by lithium; MMP-9 protein levels and enzymatic activity were also increased in MSCs, and MMP-9 protein levels were elevated in the culture medium. Although lithium increased CXCR4 and MMP2 transcripts at exceedingly high concentrations $(10-20 \mathrm{mM})$, there was no change in their levels of transcripts, protein, and/or enzymatic activities at commonly used doses $(0.5-2.5 \mathrm{mM})$ of this drug. MT1-MMP has been implicated in promoting MSC migration (Neth et al, 2006); however, lithium was unable to increase MT1-MMP expression under our experimental conditions. In addition, other ATP-competitive and non-competitive GSK-3 $\beta$ 
a

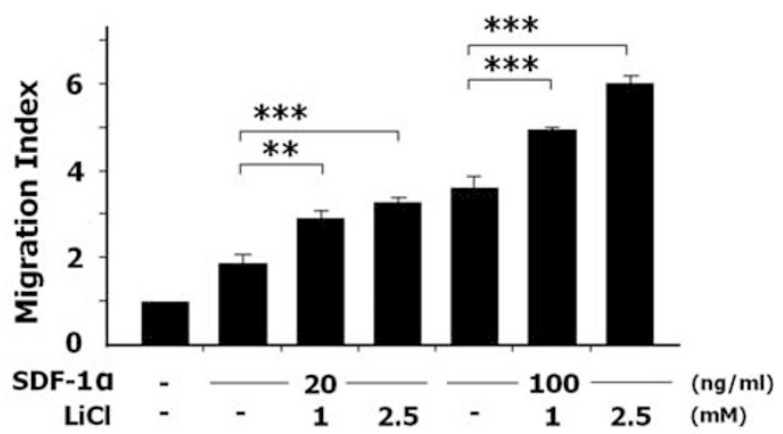

b

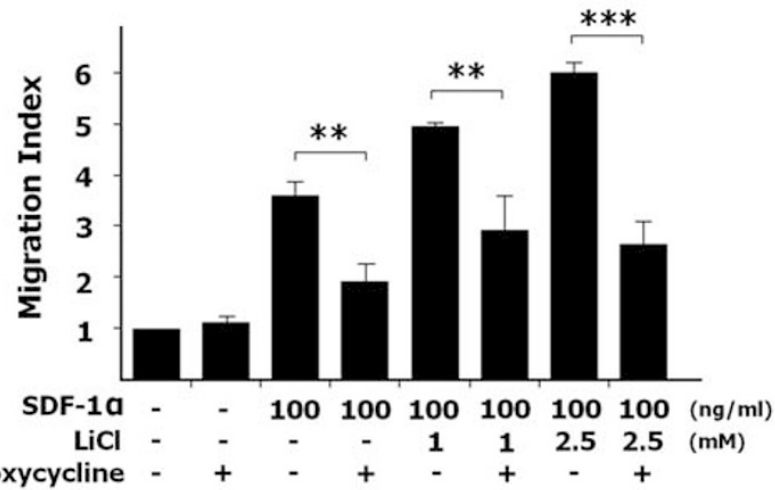

c

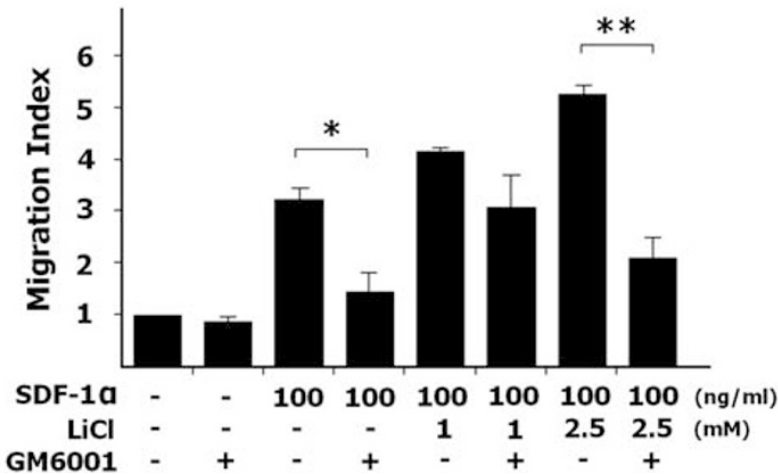

Figure $\mathbf{6}$ Lithium treatment increased migration capacity of MSCs by upregulating MMP-9. (a) Cells migrated from the upper chamber of a modified Boyden chamber across the ECM-coated membrane in $24 \mathrm{~h}$ to the lower chamber, in which SDF- $1 \alpha$ was present $(20$ or $100 \mathrm{ng} / \mathrm{ml})$. The migration index was the ratio of cell migration number in a given condition over that of the control. Pretreatment with lithium for $24 \mathrm{~h}$ increased MSC migratory capacity. (b) Co-incubating MSCs with doxycycline $(I 5 \mu \mathrm{g} / \mathrm{ml})$ blocked lithium-induced enhancement of migration. (c) Co-incubating MSCs with GM600 I $(25 \mu \mathrm{M})$ reduced lithium's effects on migration. Values are mean \pm SEM. $* p<0.05$; $* * * 0.01$; **** $p<0.00$ I between indicated groups.

inhibitors also elevated MMP-9 protein levels, as did selective silencing of GSK-3 $\beta$ using its shRNA. In rat primary astrocytes, GSK-3 $\beta$ inhibition mediates MMP-9 expression through ERK1/2 activation and subsequent NF$\kappa \mathrm{B}$ nuclear translocation (Kim et al, 2007b). Whether a similar mechanism is involved in lithium-induced MMP-9 expression in MSCs requires further investigation.

Pharmacological inhibition of MMP-9 activity by doxycycline or GM6001 abolished lithium potentiation of SDF$1 \alpha$-dependent MSC migration through the extracellular matrix, supporting the notion that MMP-9 has a role in this drug-induced effect. MMP-9 is also involved in the motility of leukocytes, cancer cells, and stem cells by degrading components of extracellular matrix molecules (Starckx et al, 2002). Conversely, migration of vascular smooth muscle cells is reduced by blocking MMP-9 expression through GSK-3 $\beta$ activation by rosiglitazone treatment (Lee et al, 2009). Moreover, MMP-9 inhibition attenuated the homing of neural stem cells in a mouse model of cerebral ischemia (Kang et al, 2008). Thus, pretreatment of MSCs with lithium to enhance MMP-9 expression through GSK-3 $\beta$ inhibition might increase the migration speed with which MSCs arrive at target lesion sites, thus improving their beneficial effects after transplantation.

The results of this study suggest that two mood stabilizers, VPA and lithium, enhance the migratory capacity of MSCs through different pathways: HDACCXCR4 for VPA, and GSK-3 $\beta$-MMP-9 for lithium. In support of this notion, we found that short-term VPA treatment did not affect MMP-9 levels and failed to increase GSK- $3 \beta^{\text {Ser9 }}$ phosphorylation. Although SDF- $1 \alpha$ and CXCR 4 can activate MMP-9 in neural stem cells (Barkho et al, 2008), we found no change in MMP-9 transcript levels after treating MSCs with a wide concentration range $(20-500 \mathrm{ng} /$ $\mathrm{ml}$ ) of SDF- $1 \alpha$ for $15 \mathrm{~h}$ (data not shown). On the other hand, treatment with lithium or knockdown of GSK-3 $\beta$ with its shRNA selectively upregulated MMP-9 with no effect on CXCR4 expression. A scheme illustrating the initial targets and mediators by which VPA and lithium enhance MSC migration is shown in Figure 8.

Because of the involvement of distinct mechanisms in VPA- and lithium-induced MSC migration, it is not surprising that combined pretreatment with both drugs produced an additive effect on cell mobility. Under these treatment conditions, levels of CXCR4, MMP-9, acetylated histone, and phospho-GSK-3 $\beta^{\mathrm{Ser} 9}$ were all time dependently increased. Recent studies from our laboratory showed that co-treatment with VPA and lithium resulted in synergistic/ additive neuroprotective effects against excitotoxicity in primary brain neurons and behavioral benefits in a mouse model of amyotrophic lateral sclerosis (Feng et al, 2008; Leng et al, 2008). Clinically, VPA and lithium are also frequently used together to treat individuals with bipolar disorder who are resistant to monotherapy with either drug (Lin et al, 2006). Overall, the evidence suggests that VPA and lithium, notably when administered together, might enhance the migratory ability of MSCs, thus possibly optimizing their effectiveness in stem cell therapy. Future in vivo experiments are mandatory to test the homing and therapeutic effects of VPA/lithium-primed MSCs in various models of human diseases.

\section{ACKNOWLEDGEMENTS}

This research was supported by the Intramural Research Program of the National Institute of Mental Health, National Institutes of Health, Department of Health and Human Services (IRP-NIMH-NIH-DHHS), by National Taiwan University Hospital, and by the HSU family gift fund. We thank Dr Chen-Hung Ting of Academia Sinica, Taiwan, for primer design in the ChIP assay, Mr Dave Luckenbaugh of the National Institute of Mental Health for 


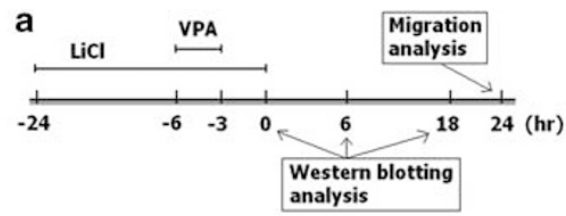

b
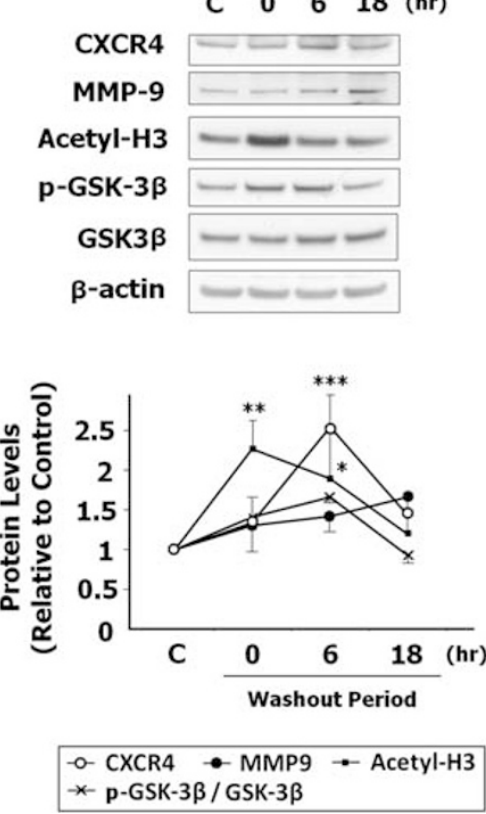

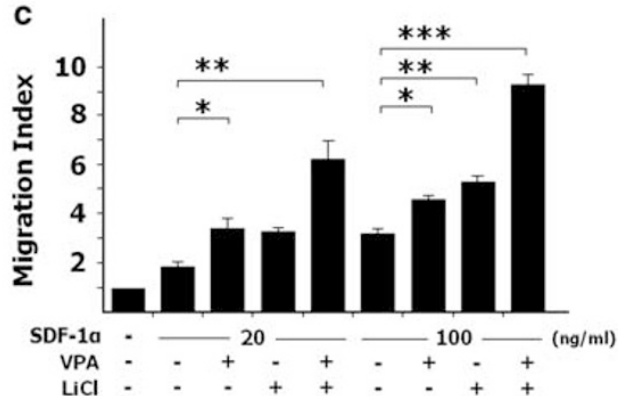

d

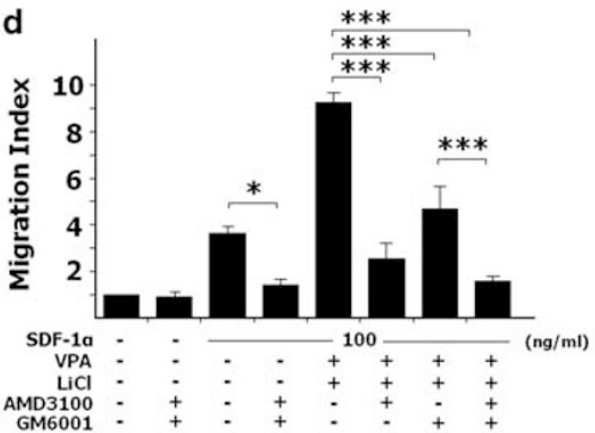

Figure 7 Additive enhancement of migratory capacity by VPA and lithium co-treatment in MSCs. (a) MSCs were treated with $2.5 \mathrm{mM}$ VPA for $3 \mathrm{~h}$ ( -6 to $-3 \mathrm{~h}$ ) and $2.5 \mathrm{mM}$ lithium for $24 \mathrm{~h} \mathrm{(-24} \mathrm{to} 0 \mathrm{~h}$ ) and then cultured with fresh medium (drug washout). Cells were harvested at 0,6 , and $18 \mathrm{~h}$ for western blotting, and cell migration experiments were initiated at $\mathrm{Oh}$ and terminated at $24 \mathrm{~h}$. (b) Acetylated histone-H3 and phospho-GSK-3 $\beta^{\text {Ser } 9}$ protein levels increased after VPA and lithium co-treatment, followed by increases of CXCR4 and MMP-9 protein. (c) MSCs in a modified Boyden chamber migrated within $24 \mathrm{~h}$ from the upper chamber across the ECM-coated membrane to the lower chamber, in which SDF- $\mid \alpha(100 \mathrm{ng} / \mathrm{ml})$ was present. The migration index was the ratio of cell migration number in a given condition over that of the control. (d) Pretreatment with VPA and lithium increased MSC migratory capacity, which was nullified by co-incubating MSCs with AMD3I00 $(5 \mu \mathrm{M})$ and GM600I $(25 \mu \mathrm{M})$ either alone or in combination. Acetyl-H3 indicates acetylated histone-H3. Values are mean \pm SEM. Data in (b) were analyzed by two-way ANOVA. $* p<0.05$; ** $p<0.0$ I; **** $p<0.00$ I when compared with control in (b) or between the indicated groups.

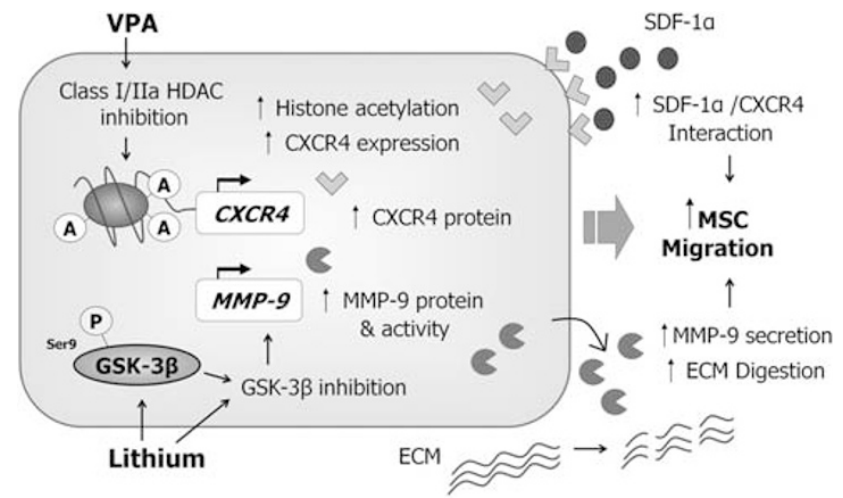

Figure 8 A schematic illustration of the actions of VPA and lithium on migration of MSCs. VPA inhibits the activity of class I/lla HDACs, leading to hyperacetylation in the promoter of the CXCR4 gene and subsequent enhancement of CXCR4 expression. Through interaction with SDF-I $\alpha$, VPA-induced CXCR4 triggers MSC migration toward regions containing higher concentrations of SDF-I $\alpha$. On the other hand, lithium inhibits GSK$3 \beta$ either directly or indirectly through phosphorylation at the Ser9 site and promotes MMP-9 expression. MMP-9 is then secreted and digests ECM to also increase MSC migration. VPA and lithium thus enhance MSC migration by differential mechanisms and their co-presence induces additive effects on the migratory capacity of MSCs. assistance in statistical analysis, and Ms Ioline Henter and Dr Joshua Hunsberger of the National Institute of Mental Health for assistance in the preparation of the paper.

\section{DISCLOSURE}

The authors declare no conflict of interest.

\section{REFERENCES}

Bai L, Lennon DP, Eaton V, Maier K, Caplan AI, Miller SD et al (2009). Human bone marrow-derived mesenchymal stem cells induce Th2-polarized immune response and promote endogenous repair in animal models of multiple sclerosis. Glia 57: 1192-1203.

Bang OY, Lee JS, Lee PH, Lee G (2005). Autologous mesenchymal stem cell transplantation in stroke patients. Ann Neurol 57: 874-882.

Barkho BZ, Munoz AE, Li X, Li L, Cunningham LA, Zhao X (2008). Endogenous matrix metalloproteinase (MMP)-3 and MMP-9 promote the differentiation and migration of adult neural progenitor cells in response to chemokines. Stem Cells 26: 3139-3349. 
Bernardo ME, Locatelli F, Fibbe WE (2009). Mesenchymal stem cells. Ann NY Acad Sci 1176: 101-117.

Brooke G, Tong H, Levesque JP, Atkinson K (2008). Molecular trafficking mechanisms of multipotent mesenchymal stem cells derived from human bone marrow and placenta. Stem Cell Dev 17: 929-940.

Centeno CJ, Busse D, Kisiday J, Keohan C, Freman M, Karli D (2008). Increased knee cartilage volume in degenerative joint disease using percutaneously implanted, autologous mesenchymal stem cells. Pain Physician 11: 343-353.

Cheng Z, Ou L, Zhou X, Li F, Jia X, Zhang Y et al (2008). Targeted migration of mesenchymal stem cells modified with CXCR4 gene to infarcted myocardium improves cardiac performance. Mol Ther 16: 571-579.

Chuang DM (2005). The antiapoptotic actions of mood stabilizers: molecular mechanisms and therapeutic potentials. Ann NY Acad Sci 1053: 195-204.

Chuang DM, Leng Y, Marinova Z, Kim HJ, Chiu CT (2009). Multiple roles of HDAC inhibition in neurodegenerative conditions. Trends Neurosci 32: 591-601.

Chuang DM, Manji HK (2007). In search of the Holy Grail for the treatment of neurodegenerative disorders: has a simple cation been overlooked? Biol Psychiatry 62: 4-6.

Clinicaltrials.gov (2010). Clinical trials of mesenchymal stem cells. Available at http://clinicaltrials.gov/ct2/results?term = mesenchymal+stem+cell. Accessed on 30 June 2010.

Dharmasaroja P (2009). Bone marrow-derived mesenchymal stem cells for the treatment of ischemic stroke. J Clin Neurosci 16: $12-20$.

Deng YB, Liu XG, Liu ZG, Liu XL, Liu Y, Zhou GQ (2006). Implantation of $\mathrm{BM}$ mesenchymal stem cells into injured spinal cord elicits de novo neurogenesis and functional recovery: evidence from a study in rhesus monkeys. Cytotherapy 8: $210-214$.

Dominici M, Blanc KL, Mueller I, Slaper-Cortenbach I, Marini FC, Krause DS (2006). Minimal criteria for defining multipotent mesenchymal stromal cells. The International Society for Cellular Therapy position statement. Cytotherapy 8: 315-317.

Einat $\mathrm{H}$, Yuan $\mathrm{P}$, Gould TD, Li J, Du J, Zhang $\mathrm{L}$ et al (2003). The role of the extracellular signal-regulated kinase signaling pathway in mood modulation. J Neurosci 23: 7311-7316.

Feng HL, Leng Y, Ma CH, Zhang J, Ren M, Chuang DM (2008). Combined lithium and valproate treatment delays disease onset, reduces neurological deficits and prolongs survival in an amyotrophic lateral sclerosis mouse model. Neuroscience 155: 567-572.

Göttlicher M, Minucci S, Zhu P, Kramer OH, Schimpf A, Giavara S et al (2001). Valproic acid defines a novel class of HDAC inhibitors inducing differentiation of transformed cells. EMBO J 20: 6969-6978.

Gul H, Marquez-Curtis LA, Jahroudi N, Lo J, Turner AR, Janowska-Wieczorek A (2009). Valproic acid increases CXCR4 expression in hematopoietic stem/progenitor cells by chromatin remodeling. Stem Cells Dev 18: 831-838.

Haddad PM, Das A, Ashfaq M, Wieck A (2009). A review of valproate in psychiatric practice. Expert Opin Drug Metab Toxicol 5: 539-551.

Hare JM, Traverse JH, Henry TD, Dib N, Strumpf RK, Schulman SP et al (2009). A randomized, double-blind, placebo-controlled, dose-escalation study of intravenous adult human mesenchymal stem cells (prochymal) after acute myocardial infarction. $\mathrm{J} \mathrm{Am}$ Coll Cardiol 54: 2277-2286.

Huang CY, Lee CY, Chen MY, Yang WH, Chen YH, Chang CH et al (2009). Stromal cell-derived factor-1/CXCR4 enhanced motility of human osteosarcoma cells involves MEK1/2, ERK and NF-KB-dependent pathways. J Cell Physiol 221: 204-212.
Jiang J, Au M, Lu K, Eshpeter A, Korbutt G, Fisk G et al (2007). Generation of insulin-producing islet-like clusters from human embryonic stem cells. Stem Cells 25: 1940-1953.

Kang SS, Kook JH, Hwang S, Park SH, Nam SC, Kim JK (2008). Inhibition of matrix metalloproteinase- 9 attenuated neural progenitor cell migration after photothrombotic ischemia. Brain Res 1228: 20-26.

Karp JM, Leng Teo GS (2009). Mesenchymal stem cell homing: the devil is in the details. Cell Stem Cell 4: 206-216.

Katoh M (2010). Integrative genomic analyses of CXCR4: transcriptional regulation of CXCR4 based on TGFbeta, Nodal, Activin signaling and POU5F1, FOXA2, FOXC2, FOXH1, SOX17, and GFI1 transcription factors. Int J Oncol 36: 415-420.

Kim AJ, Shi Y, Austin RC, Werstuck GH (2005). Valproate protects cells from ER stress-induced lipid accumulation and apoptosis by inhibiting glycogen synthase kinase-3. J Cell Sci 118: 89-99.

Kim HJ, Leeds P, Chuang DM (2009). The HDAC inhibitor, sodium butyrate, stimulates neurogenesis in the ischemic brain. J Neurochem 110: 1226-1240.

Kim HJ, Rowe M, Ren M, Hong JS, Chen PS, Chuang DM (2007a). Histone deacetylase inhibitors exhibit anti-inflammatory and neuroprotective effects in a rat permanent ischemic model of stroke: multiple mechanisms of action. J Pharmacol Exp Ther 321: 892-901.

Kim SD, Yang SI, Kim HC, Shin CY, Ko KH (2007b). Inhibition of GSK-3 $\beta$ mediates expression of MMP-9 through ERK1/2 activation and translocation of NF- $\kappa \mathrm{B}$ in rat primary astrocyte. Brain Res 1186: 12-20.

Kitaori T, Ito H, Schwarz EM, Tsutsumi R, Yoshitomi H, Oishi S et al (2009). Stromal cell-derived factor 1/CXCR4 signaling is critical for the recruitment of mesenchymal stem cells to the fracture site during skeletal repair in a mouse model. Arthritis Rheum 60: 813-823.

Koch-Weser J, Browne TR (1980). Drug therapy: valproic acid. $N$ Engl J Med 302: 661-666.

Kumar S, Chanda D, Ponnazhagan S (2008). Therapeutic potential of genetically modified mesenchymal stem cells. Gene Therapy 15: 711-715.

Lee CS, Kwon YW, Yang HM, Kim SH, Kim TY, Hur J et al (2009). New mechanism of rosiglitazone to reduce neointimal hyperplasia: activation of glycogen synthase kinase- $3 \beta$ followed by inhibition of MMP-9. Arterioscler Thromb Vasc Biol 29: 472-479.

Leng Y, Chuang DM (2006). Endogenous $\alpha$-synuclein is induced by valproic acid through histone deacetylase inhibition and participates in neuroprotection against glutamate-induced excitotoxicity. J Neurosci 26: 7502-7512.

Leng Y, Liang MH, Ren M, Marinova Z, Leeds P, Chuang DM (2008). Synergistic neuroprotective effects of lithium and valproic acid or other histone deacetylase inhibitors in neurons: roles of glycogen synthase kinase-3 inhibition. J Neurosci 28: 2576-2588.

Lin D, Mok H, Yatham LN (2006). Polytherapy in bipolar disorder. CNS Drugs 20: 29-42.

Lindvall O, Kokaia Z (2010). Stem cells in human neurodegenerative disorders - time for clinical translation? J Clin Invest 120: 29-40.

McEloroy SL, Keck Jr PE (1995). Antiepileptic drugs. In: Schatzberg AF, Nemeroff CB (eds). Textbook of Psychopharmacology. American Psychiatric Publishing: Washington, DC. pp 351-375.

Neth P, Ciccarella M, Egea V, Hoelters J, Jochum M, Ries C (2006). Wnt signaling regulates the invasion capacity of human mesenchymal stem cells. Stem Cells 24: 1892-1903.

Neth P, Ries C, Karow M, Egea V, Ilmer M, Jochum M (2007). The Wnt signal transduction pathway in stem cells and cancer cells: influence on cellular invasion. Stem Cell Rev 3: 18-29.

Parekkadan B, Milwid JM (2010). Mesenchymal stem cells as therapeutics. Annu Rev Biomed Eng 12: 87-117. 
Phiel CJ, Zhang F, Huang EY, Guenther MG, Lazar MA, Klein PS (2001). Histone deacetylase is a direct target of valproic acid, a potent anticonvulsant, mood stabilizer, and teratogen. J Biol Chem 276: 36734-36741.

Price LH, Heninger GR (1994). Lithium in the treatment of mood disorders. N Engl J Med 331: 591-598.

Prockop DJ (1997). Marrow stromal cells as stem cells for nonhematopoietic tissues. Science 276: 71-74.

Raz E, Mahabaleshwar H (2009). Chemokine signaling in embryonic cell migration: a fisheye view. Development 136: $1223-1229$.

Ren M, Leng Y, Jeong M, Leeds PR, Chuang DM (2004). Valproic acid reduces brain damage induced by transient focal cerebral ischemia in rats: potential roles of histone deacetylase inhibition and heat shock protein induction. J Neurochem 89: 1358-1367.

Segers VF, Tokunou T, Higgins LJ, MacGillivray C, Gannon J, Lee RT (2007). Local delivery of protease-resistant stromal cell derived factor-1 for stem cell recruitment after myocardial infarction. Circulation 116: 1683-1692.
Starckx S, Van den Steen PE, Wuyts A, Van Damme J, Opdenakker G (2002). Neutrophil gelatinase B and chemokines in leukocytosis and stem cell mobilization. Leuk Lymphoma 43: 233-241.

Thieme S, Ryser M, Gentsch M, Navratiel K, Brenner S, Stiehler M et al (2009). Stromal cell-derived factor-1alpha-directed chemoattraction of transiently CXCR4-overexpressing bone marrow stromal cells into functionalized three-dimensional biomimetic scaffolds. Tissue Eng Part C Methods 15: 687-696.

Vercelli A, Mereuta OM, Garbossa D, Muraca G, Mareschi K, Rustichelli D et al (2008). Human mesenchymal stem cell transplantation extends survival, improves motor performance and decreases neuroinflammation in mouse model of amyotrophic lateral sclerosis. Neurobiol Dis 31: 395-405.

Verheyen EM, Gottardi CJ (2010). Regulation of Wnt/ $\beta$-catenin signaling by protein kinases. Dev Dyn 239: 34-44.

Wang Y, Deng Y, Zhou GQ (2008). SDF-1alpha/CXCR4-mediated migration of systemically transplanted bone marrow stromal cells towards ischemic brain lesion in a rat model. Brain Res 1195: 104-112.

Supplementary Information accompanies the paper on the Neuropsychopharmacology website (http://www.nature.com/npp) 